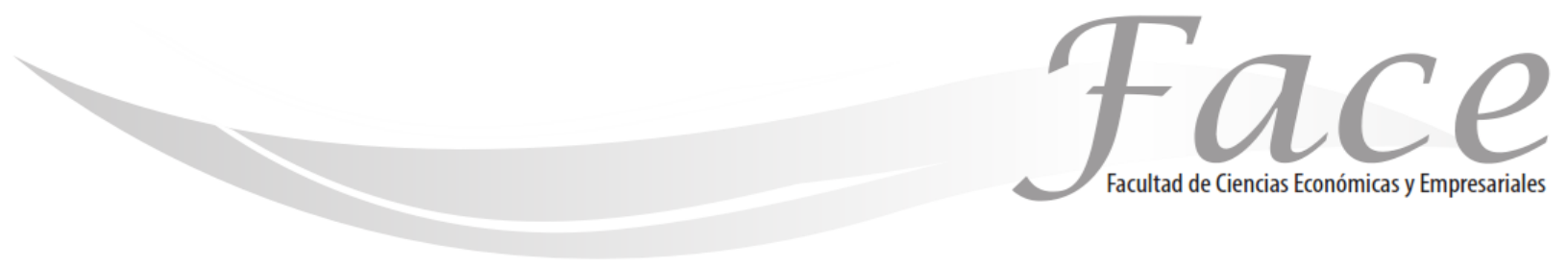

ISSN Impreso: 1794-9920

ISSN Electrónico: 2500-9338

Volumen $18-\mathrm{N}^{\circ} 1$

Año 2018

Págs. 82 - 91

\title{
DEL AVATAR AL CYBORG: APROXIMACIONES CONCEPTUALES Y TEÓRICAS
}

\author{
Ena Yuritze Barón L * \\ Enlace ORCID: https://orcid.org/0000-0002-2659-450 \\ Dulce María de L. Bautista Luzardo ** \\ Enlace ORCID: https://orcid.org/0000-0002-1989-6199
}

Fecha de Recepción: 12 de Marzo 2018

Fecha de Aprobación: 20 de Junio 2018

\section{Resumen:}

El presente artículo es una revisión descriptiva de los términos cyborg, avatar y cibermarketing, a la luz de las teorías contemporáneas y además de revisar la relación del avatar y el ciborg, en cuanto a la tendencia de representar el cuerpo mediante alter egos o personajes artificiales. Por otra parte, se busca llamar la atención sobre la importancia de los avatares en las nuevas construcciones de imaginarios en el ámbito del marketing.

Las indagaciones iniciales de esta investigación provienen del trabajo doctoral de la profesora Dulce María Bautista más adelante con el propósito aprovechar la importancia de este tema para el campo del marketing se realizó la investigación sobre portadores de marca alcances semióticos y culturales en 2017 en el departamento de Mercadología de la Universidad Central de Bogotá, de esta última investigación hay una ponencia en el III congreso internacional de investigación de la Red Radar Colombia 2018.

Palabras Clave: Avatar Cyborg, Cuerpo, Virtual.

* Doctora en Ciencias Sociales y humanidades, posdoctora en Educación Comunicación y Cultura. Investigadora principal del área de cultura y marketing. Correo Electrónico: dbautistal1@ucentral.edu.co

**. Magíster en economía, derecho y gestión con especialidad en investigación de marketing y Mercadóloga. Coinvestigadora del área de Marketing en el campo de la personalidad de marca y portadores. Departamento de Mercadología Universidad Central Bogotá. Correo Electrónico: ebaronl@ucentral.edu.co 


\title{
FROM AVATAR TO CYBORG: CONCEPTUAL AND THEORETICAL APPROACHES
}

\begin{abstract}
:
This article is a descriptive review of the terms cyborg, avatar and cybermarketing, in light of contemporary theories and in addition to review the relationship of the avatar and the cyborg, in terms of the tendency to represent the body through alter egos or artificial characters. On the other hand, it seeks to draw attention to the importance of avatars in the new constructions of imaginaries in the field of marketing.

The initial inquiries of this research come from the doctoral work of Professor Dulce Maria Bautista later in order to take advantage of the importance of this topic for the field of marketing research was carried out on brand carriers semiotic and cultural reaches in 2017 in the department of Marketing of the Central University of Bogotá, from this latest research there is a presentation at the III International Research Congress of the Radar Network Colombia 2018.
\end{abstract}

Keywords: Avatar Cyborg, Body, Virtual.

\section{DE AVATAR A CYBORG: ABORDAGENS CONCEITUAIS E TEÓRICAS}

\section{Resumo:}

Este artigo é uma revisão descritiva dos termos cyborg, avatar e cybermarketing, à luz de teorias contemporâneas e além de revisar a relação do avatar com o cyborg, em termos da tendência de representar o corpo através de alter egos ou de caracteres artificiais. Por outro lado, procura chamar a atenção para a importância dos avatares nas novas construções de imaginários no campo do marketing.

Os inquéritos iniciais desta pesquisa vêm do trabalho de doutorado da professora Dulce María Bautista mais tarde, a fim de aproveitar a importância deste tema para o campo de pesquisa de marketing foi realizado em transportadoras de marca semiótica e cultural atinge em 2017 no departamento de Marketing da Universidade Central de Bogotá, a partir desta última pesquisa, há uma apresentação no III Congresso Internacional de Pesquisa da Rede Radar Colômbia 2018..

Palavras chave: Avatar Cyborg, Corpo, Virtual. 
ISSN: 1794-9920 - ISSN Electrónico: 2500-9338

Enero - Julio de 2018

Volumen 18 Número 1, Año 2018 Págs. 82 - 91

\section{INTRODUCCIÓN:}

En la actualidad se están encontrando cada vez con mayor fuerza figuras de seres ficticios que sirven como motivadores en diferentes ámbitos; estas imágenes se encuentran en diversos lugares del ciberespacio y llegan a convertirse en influenciadores del consumo.

En el marketing, el concepto de innovación basada en el avatar sirve como un punto de origen para revelar posibilidades y representa el primer intento de aprovechar sistemáticamente los mundos virtuales para la gestión con el consumidor. Estudios contemporáneos de MIT. Coleman (2018) propone que estamos continuamente bombardeados por esperanzas de felicidad que solo son posibles si nos actualizamos en el mundo de los avatares. (Coleman \& Shirky, 2011) revelan que nuestros comportamientos online, dicen mucho de lo que ocultamos o de lo que deseamos de la vida física.

Al respecto, son destacables también los estudios y las propuestas de Matt Beane (2018) que estudia los efectos de la telepresencia y la robótica y las propuestas de D. Fox Harrell (2018) acerca de los impactos que pueden tener los avatares en la identidad humana (Harrell, 2018)

En el marketing el avatar es un elemento grafico de gran importancia que permite mejorar la experiencia de consumo para las diferentes marcas ya que implica una asociación de valores entre el avatar y los productos.

En el cibermarketing es muy importante construirse un cuerpo para si se quiere innovar e influenciar con éxito a los consumidores potenciales y de ello se están encargando las empresas fabricantes de avatares. La apariencia es una de las mayores motivaciones a las cuales se les invierte más tiempo y dinero. El hecho de construirse un cuerpo tiene implicada toda una filosofía de ciber vida que la otorgan los dueños de las marcas y se encargan de mantener con un estatus importante al creado avatar 0 a veces puede tratarse también de un cyborg 0 un robot.

En la actualidad, varias compañias se encuentran produciendo robots cuyos antecesores son también los avatares (inclusive VGo, iRobot's Ava, y Willow Garage's Texai) cuyos usuarios pueden navegar e interatuar a través de control remoto. (Traducción libre de Bautista $\mathrm{L}$. Dulce M.) Los trabajos presentados desde (ECM Benchmarking Report - European Cities Marketing, 2018)
En la revision de fuente primaria se ha encontrado que la principal fuente de desarrollos temáticos del tema, en la actualidad es MIT, por lo cual se refieren los siguientes enlaces, actualizados a 2018:

- https://www.europeancitiesmarketing.com/europe an-cities-marketi...(2018) avalan este punto de vista

Generar avatares on Scratch - MIT (2018)https://scratch.mit.edu/projects/26838360/;

- $\quad$ Y Crea tu propio personaje de Doki on Scratch -

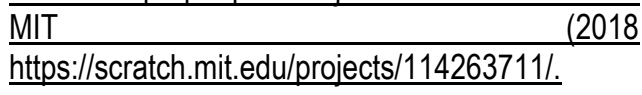

Expuesto lo anterior, el presente artículo busca reflexionar a partir de la esta revisión conceptual y teórica acerca de cuál es el papel de estos nuevos seres no-seres que, con cuerpos extraordinarios y expresiones humanas han llegado a intervenir en la cotidianeidad de las personas y como contribuyen a la innovación en las estrategias de marketing.

Específicamente sobre este artículo, dada la actualidad y el interés de este tema para el marketing las autoras presentan una indagación conceptual y teórica de los términos cyborg, avatar y cibermarketing para evidenciar la relación con el marketing; de otra parte, se busca reflexionar sobre la importancia de los avatares en las nuevas construcciones de imaginarios en el ámbito de esta disciplina; de allí que la discusión de este artículo se centre sobre la reflexión hacia la pregunta ¿Cuál es la diferencia entre el Cyborg y el Avatar y cuáles son las características de los contextos en los que se encuentran inmersos? Además, las autoras también relacionan este papel con la función estratégica de estos seres para las marcas. 


\section{METODOLOGÍA:}

Con el fin de conocer los posibles conceptos relacionados con el tema de interés se hizo una exploración de fuentes impresas de tipo primario como artículos de revista, artículos científicos, los aportes del MIT (Massachusetts Institute of Technology, por sus siglas), y las averiguaciones conceptuales originales del trabajo doctoral sobre second life desarrollado por la doctora Dulce María Bautista L.

De acuerdo con Strauss, la búsqueda de significados derivados de la literatura existente permite comparara entre lo que el investigador cree y las consideraciones de otros expertos 0 investigadores del tema en segundo lugar también conduce a que el investigador este familiarizado con la literatura pertinente y tercero aumenta la sensibilidad y la posibilidad de hacer nuevas preguntas (Strauss, 2002)

\section{REVISIÓN TEÓRICA:}

\section{Conceptos relacionados con los Cyborg, los avatares y el cuerpo.}

La necesidad de fabricarse un cuerpo y más que eso una apariencia, quizás venga de las nostalgias de saberse incompletos como seres humanos, como lo ha evidenciado muy bien críticamente Bruno Latour (2007). Pero de esta necesidad, las grandes empresas se apropian y convierten todo este andamiaje en la posibilidad de jugar a "ser otro" o a intervenirse. En muchas ocasiones, esta imagen que representa los deseos por cumplirse de los seres humanos en busca de su completitud corresponde a prácticas motivadoras de la creación de personajes que buscan hacer sentir a otros, en este caso a los consumidores de su importancia en el mundo (Latour, 2007)

Pero la construcción de un cuerpo no es únicamente una acción propia del cibermercado. El body art, es una forma de expresión artística en la cual el cuerpo se vuelve escena o protagonista de un escenario; es una forma de hacer con cuerpo un performance, que se puso de moda a fines de los años 90's y en muchas ocasiones tenía intenciones de hacer resistencia o manifestar una protesta contra el mundo establecido en donde el cuerpo debe responder a un modelo capitalista. Pero en la actualidad aquellos primeros propósitos se quedaron en la historia del arte y hoy se busca desarrollar un modelo más efectista que comunique rápido sin tantas explicaciones.
Kac (1997) es uno de esos artistas del Body art que recurre al concepto personal del cuerpo como herramienta y como vehículo que comunica. Al respecto se puede mencionar la creación de Cyborgs. Edward Kac busca señalar la postura del yo en la cotidianeidad, influida culturalmente; por eso aparece el cuerpo puesto en escena como organismo artístico, el artista quiere enfatizar en los conceptos de telepresencia y bioarte, para demostrar que en internet el cuerpo puede ser intervenido, mediante interconexiones de redes, humanos y especies animales (Kac, 1997) Esta telepresencia se volvió uno de los grandes pretextos para que las marcas piensen en mostrar cuerpos cotidianos, cuerpos singulares 0 cuerpos intervenidos que espectacularizan la realidad y en este momento, también la ciber realidad.

Los trabajos de Paula Sibilia (2008) critican la forma como en la contemporaneidad se usa el cuerpo como instrumento de poder y dominación, desligándolo del verdadero sentido humanista. La autora afirma que es una moda tener un cuerpo de tal o cual forma, y que esta moda es el producto del descontento del ser humano con la contemporaneidad.

Para demostrar sus argumentos, Sibilia menciona los trabajos de Kac como posturas críticas a las formas tradicionales de ver y representar el cuerpo y a las formas contemporáneas de manipular la imagen personal hasta llegar a deformarla (Sibilia, 2006)

De hecho, aunque la autora no menciona en particular el término Cyborg, se refiere a cuerpos intervenidos por prótesis electrónicas a propósito de la obra de Kac, en la cual se inspira para teorizar y problematizar al cuerpo y a la imagen exterior como el efecto disociado de mentes "esquizofrénicas" como califica a los seres humanos contemporáneos.

Sin embargo, estas fuertes críticas quedaron como un marco de referencia desde el cual ahora se puede asumir el mundo más allá de las luchas de poderes y más en cuanto a las luchas personales por alcanzar un puesto en el que cada uno de desarrolla y actúa, porque lo cierto es que nos encontramos en un mundo en donde el cuerpo se 
ISSN: 1794-9920 - ISSN Electrónico: 2500-9338

Enero - Julio de 2018

Volumen 18 Número 1, Año 2018 Págs. 82 - 91

ha intervenido más allá de la idea de puesta en escena artística y se le ha dado connotación de cyborg, para incluirlo dentro del mundo de la producción, la telepresencia y la ciberproducción.

\section{el cyborg como evolución del cuerpo intervenido, en el mundo tangible}

En algunas empresas han comenzado a surgir bellas figuras humanas que interactúan con los clientes y entablan una nueva comunicación, más dinámica y divertida.

Esta nueva forma de comunicación y las novedosas concepciones respecto a las tecnologías aplicadas al marketing, comienzan a abrir un mundo en donde la mente humana hace realidad sus fantasías, entre ellas las de tener del otro lado de una pantalla o en compañía del celular, a otro ser que es solo una imagen (no-ser), pero en el fondo muchos consumidores corroboraron que ya la tecnología había crecido tanto, que podía esperarse incluso que las máquinas hablaran, como efectivamente ocurrió en Japón con los robots que tienen características humanas.

Desde la creación del movimiento llamado ciberpunk, las tendencias tecnológicas han buscado crear estos mundos en donde las máquinas pueden intervenir el cuerpo a la manera de prótesis de los seres humanos, el cual ha sido considerado como un momento importante en la evolución del marketing mundial.

Existen ensambles telemáticos y transformaciones del cuerpo de los seres humanos, que se intervienen para tener nuevas experiencias que alteran sus sentidos, como por ejemplo, imanes en los dedos, o una prótesis con la que se interviene el cerebro, como en el caso de Neil Harbisson, quien tiene una antena conectada a su cráneo y puede percibir variaciones en la manera de interpretar los colores y los olores entre otros, noticia que recientemente nos mostró que el body art, ya ha sido llevado a evoluciones en donde el hombre quiere experimentar distintas sensaciones respecto al cuerpo.

El mismo Harbisson (2018) se autodenomina Cyborg y así ha entrado en el mundo inglés, aceptado con su prótesis incluso en los aeropuertos. Pero esta nueva manera de experimentar el mundo llama la atención de las marcas y de los creativos publicitarios que con mucha frecuencia sueñan con un chip mágico que les cambie la vida a los consumidores (Nora, 2018).

\section{¿Qué es cyborg?}

Para Aguilar (2008:13) el término cyborg "es definido por primera vez por Clynes y Kline en 1960 al intentar describir a un individuo mejorado capaz de sobrevivir en el espacio y (Haraway, 1996) como un organismo cibernético, un híbrido de máquina y organismo, una criatura de realidad social y también de ficción, el cyborg (Cybernetic Organism) adquiere una representatividad propia de la última década del siglo XX." (Aguilar, 2008)

Pero es en este siglo (XXI), cuando se presentifica de una manera que supera el arte y se convierte en un ser vivo entre nosotros, cableado e informado de prótesis que alteran las percepciones sensoriales, como es el caso de Harbisson que se acaba de mencionar.

Como puede observarse, el concepto de cuerpo se ha transformado de cuerpo físico a cuerpo artístico (como es el caso del Body art), cuerpo digitalizado (como es el caso de la construcción de avatares para funcionar en los metaversos y en especial en publicidad como influenciadores, portadores o embajadores de marca).

Entonces los cuerpos, según los autores mencionados, sufren una especie de metamorfosis que para la tecnología, son formas de ser nuevas de los cuerpos. Independientemente del llamado ciberespacio, algunos artistas han visto la posibilidad de traer cuerpos inventados en el ciberespacio al mundo real. Este es el caso de Edward Kac, quien ha expuesto cuerpos intervenidos por prótesis, para demostrar que el cuerpo comunica en diversos espacios (Kac, 1997)

Kac propone implantar prótesis en cuerpos humanos, se podría decir que está sacando del mundo de la pantalla el hecho de hacerse a un cuerpo distinto. Pero en el momento en que lo propuso, no alcanzó a dimensionar hasta qué punto se podría volver tendencia y en particular en el campo del marketing, en la actualidad por ejemplo hay una tendencia sobre el avatar consumidor que es como un dummie de un cliente ideal de una empresa que es basado en la información de estudios de mercado de los posibles consumidores, es decir funciona como un consumidor de verdad, por eso es importante que para crearlo se tenga la información mas precisa como la edad 
promedio, profesiones, nombres, aspectos, psicológicos, psicográficos (brandlective, 2018).

Entonces "El cuerpo se revela como inservible sin las prótesis tecnológicas que lo capacitan para funcionar en el mundo actual. La ampliación del cuerpo humano por el aparato tecnológico es el nuevo reto que los sujetos de las sociedades emergentes deben plantearse como aceptación incondicional de una nueva naturaleza (...) naturaleza cyborg y a su vez la construcción de un nuevo individuo no estrictamente humano". (Aguilar, 2008). Frank Swain es un editor de New Scientist, y el presentador de "Meet The Cyborgs", un documental sobre potenciadores corporales que se emitió recientemente en la BBC Radio 4.

Su propio viaje en ciborg comenzó hace unos cinco años, cuando le diagnosticaron sordera precoz y equipado para audífonos"Me interesaba la forma en que aumentaban mi realidad", me dice Frank. "Suprimen mucho de lo que consideran ruido, como el viento o el tráfico, y amplifican los sonidos que creen que son útiles, como las voces. Decidí que, si iba a escuchar una versión interpretativa del mundo por el resto de mi vida, quería desempeñar un papel en el proceso de editorialización " (brandwatch, 2017)

Illouz opina que "La tecnología de internet funde dos importantes lógicas culturales o formas de reclutamiento del yo: la de la psicología y la del consumismo. Al utilizar y basarse en la lógica del consumismo y la psicología, internet radicaliza la demanda de que se haga el mejor negocio (económico y psicológico)." (Illouz, 2007) En tanto para Joyanes (1997:15) el ciberespacio aunque parezca intangible permite interconexiones que convierten a los seres y sus existencias dentro de él a la manera de redes globales por las cuales se puede navegar y le da consistencia a las acciones que allí ocurren.

Según este autor, el ciberespacio sirve para eliminar fronteras, acortar distancias y actualmente trabajar en tiempo real mediante la interactividad que puede verse como "la aparición de nuevas relaciones socioeconómicas y vivenciales construidas sobre la ubicuidad virtual de personas, cosas y hechos" (Joyanes, 1997) Esta ubicuidad virtual ha ido perdiendo el sello de intangible y se ha vuelto cada vez más "real" para usuarios que permanecen muchas horas conectados a la red.
Sloderdijk, citado por Aguilar, considera que el ciberespacio es tanto una forma de inmersión en los territorios digitales, como el comienzo de una inmersión en el mundo virtual (Aguilar, 2008).

Al respecto dice que ahora nos enfrentamos a la construcción de la experiencia de lo real a través de la alternancia realidad-realidad virtual, quizá porque consideramos que esta última es equiparable al mundo onírico y que, tras esa diferenciación o contraste, los humanos de la era hipertecnológica serán capaces de conquistar un nuevo sentido de la realidad." Schroeder (2002) considera que una imagen corporal futurista ha suplantado y expresado en la cultura visual, especialmente en las comunicaciones de publicidad y marketing. La publicidad a menudo actúa como un barómetro psicológico, midiendo las preocupaciones y ansiedades prevalecientes en una sociedad determinada (Campbell, 2005)

\section{Imagen $\mathrm{N}^{\circ} 1$}

\section{Cybor Femenino}

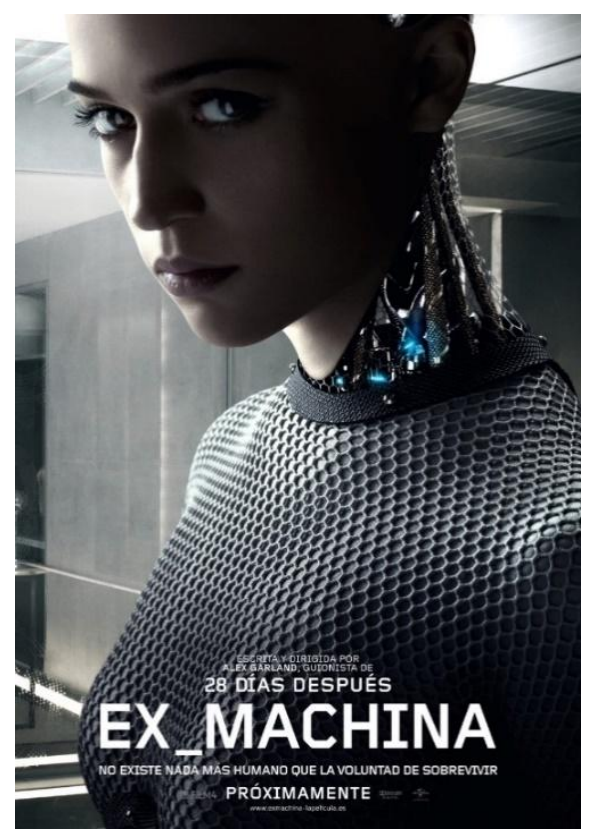

Póster español de Ex-machina del director Alex Garland 
ISSN: 1794-9920 - ISSN Electrónico: 2500-9338

Enero - Julio de 2018

Volumen 18 Número 1, Año 2018 Págs. 82 - 91

Un buen ejemplo de cómo la industria del cine mainstream

mitifica la imagen del cyborg femenino como sexi,

inteligente, frio y racional, se puede ver en la película

Ex_machina del director británico Alex Garland

(Cinemania, 2014).

\section{Lo virtual antecede el nacimiento del avatar}

Lo virtual ha influido fuertemente en las generaciones de los siglos XX y XXI. Joyanes lo define como una energía, como si fuera un impulso inicial que no es solamente ilusión o fantasía sino que también es real y dinámica (Joyanes, 1997)

El autor afirma que "fundamentalmente, la virtus actúa. Es a la vez la causa inicial en virtud de la cual el efecto existe, y por ello mismo, aquello por lo cual la causa sigue estando presente virtualmente en el efecto".

Según lo que se viene diciendo, lo virtual es una de las manifestaciones de las propias realidades humanas, a la cual el autor la relaciona con el sueño. Además, este aspecto se puede complementar considerando que las realidades virtuales se componen de imágenes que conforman mundos; algunos de estos mundos como por ejemplo los de los videojuegos, se encuentran completamente controlados.

En cambio en los metaversos, particularmente en aquellos en donde existen market place, y en donde funcionan los avatares que pueden hacer de los influenciadores, estos se comportan con cierto grado de autonomía, la que les da las características de los videojuegos, para lo cual se crean imágenes de aquellos avatares que puedan responder al gusto de las tensiones originadas por la oferta y la demanda.

La publicidad ha sabido aprovechar la virtualidad para posicionar las marcas a través de la experiencia de los juegos, un exitoso ejemplo es el de la marca Pepsi, con el video Juego Pepsiman (Merca2.0, 2015). El juego fue desarrollado a finales de los 90's para PlayStation, en el juego el hombre Pepsi debe obstáculos saltar y correr. Este concepto en la publicidad se conoce como advergaming y se trata de exponer las marcas en entornos virtuales de juegos de video en donde las marcas pueden hacer parte del escenario o pueden ser las protagonistas de los juegos.
Imagen $\mathrm{N}^{\circ} 2$

Pepsiman

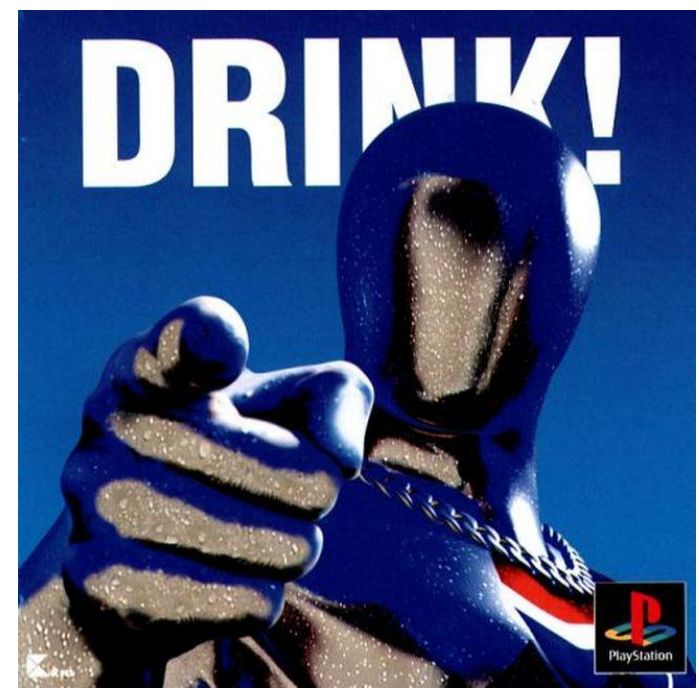

Pepsiman un juego de PlayStation

¿Será posible que, en pocos años, estas manifestaciones virtuales cambien las percepciones de productos y servicios para el consumidor? ¿Cómo aportarían estos cambios con robots, animaciones y mensajes a propuestas novedosas y diferentes de las que en el marketing hacían los portadores o embajadores de marca en el siglo pasado? ¿De qué forma podríamos concebir el mundo del marketing, si se incorporan estas nuevas emociones? ¿Qué tanto puede variar el marketing clásico respecto a estas nuevas técnicas para el posicionamiento de productos y servicios? 
Por ahora, es necesario advertir al lector que, respecto al cuerpo como apariencia (avatar), al comercio y al sentido del juego como una manera de utilizar la idea de la novedad en favor del posicionamiento de productos se ha tornado en una tendencia cuyas dinámicas sorprenden cada vez más.

Según Perales (2010), las nuevas redes globales permiten la creación de un nuevo comercio libre de ataduras geográficas que abre los espacios de mercado que hacen a las personas consumidoras de símbolos. Gracias a la conectividad de las redes electrónicas el cuerpo también se vuelve un objeto, un símbolo que no existe de manera fría, sino que requiere de una construcción (Perales, 2010).

\section{El avatar}

Con el nombre de avatar se conoce a la representación humana o animal creada por un usuario de Internet, particularmente de las redes sociales, para poder comunicarse. Algunos usuarios piensan que su avatar es un títere, mientras que para otros es un vehículo que utilizan las personas para interactuar virtualmente, incluidas las redes sociales. Con el tiempo se han introducido variantes en la apariencia del avatar humano y se han despreciado las formas animales o robóticas para hacer el avatar. El concepto de Avatar ya es conocido en la jerga de la publicidad y el mercadeo. Byron Reeves and Leighton Read comentaban ya en 2010.

Y por extraño que parezca, miles de empleados del mundo real están empezando a usar avatares como parte de sus trabajos regulares. Nuestra investigación ha demostrado cómo los empleados de compañías estadounidenses como IBM, Accenture, Cisco, State Farm, Intel, BP y Wells Fargo inician sesión en los mundos virtuales y utilizan avatares para intercambiar ideas con colegas, reclutar empleados, vender a clientes, asistir a capacitación de liderazgo, administrar programas, dirija centros de operaciones y colabore con grupos de empresas de todo el mundo (Reeves \& Read, 2010)

Sin embargo, la palabra avatar en la mitología hindú, se usa para designar un cuerpo temporalmente utilizado por un espíritu 0 por un dios cuando bajaba a la tierra. En sánscrito arcaico, avatara es "paso hacia abajo". Esta palabra se usó por primera vez para designar la forma visual o sonora de un usuario que entra en el ciberespacio (Machado, 2004)
Los avatares se encuentran en "sitios" a la manera de salas 0 cafés virtuales de internet, para intercambiar opiniones, jugar o recibir clases o simplemente como los habitantes de una ciudad (un ambiente parecido al mundo tangible) en la cual se desarrollan acciones no sólo sociales, sino también comerciales. Se les crea una historia, una vida, para que no aparezcan de pronto, sin más y cada vez se parecen más a los humanos.

Machado, citado por Turkle (1997) opina que "el anonimato de esos ambientes les da a las personas la oportunidad de explotar múltiples personalidades y experimentar diferentes aspectos de la subjetividad, jugar con su propia identidad y ensayar otras" (Turkle, 1984)(Traducción libre de Dulce María Bautista L.) De estos aspectos se apropia el cibermercado y les crea situaciones a los avatares para que se comuniquen con los seres humanos cada vez con mayor autonomía. En este proceso, el cibermercado va poniendo las pautas que luego espera volver tendencias, sobre todo en las redes.

Es importante enfatizar en que, en todos los casos, estas nuevas formas de "personalizarse" en un avatar requieren un proceso. La tecnología digital comenzó a desarrollarse con fuerza en 1978, por lo tanto, se considera que los que nacieron después de 1979 y tuvieron a su alcance en el hogar, establecimientos de estudio y de recreación computadoras o celulares pueden considerarse Nativos Digitales. Éste término fue acuñado por John Michipulengo, apareciendo por primera vez en su libro Inmigrantes Digitales en 2010 (Bautista, 2013)

Este proceso implica una especie de ajuste que también podemos llamar "consenso" entre ideas, fantasías, atributos y posibilidades de "ser" como el usuario se lo imagina. Es como si fabricar un avatar implicara pensar cómo quiere el cabello, qué gestos hará, cómo será su "personalidad" de avatar. Luego, cuando se le dan atributos de influenciador o de portador de marca, por ejemplo, habrá que crearle una historia y un discurso convincente para que la comunicación llegue adecuadamente al consumidor y surta el efecto esperado, para el cual fue creado.

Si la persona tiene un soma o un cuerpo físico, el avatar 0 el usuario de Internet posee una forma representativa con la cual desea darse a conocer o mostrarse. En el mundo físico, muchos seres humanos tienen dificultad para aceptarse respecto a otro. Pero con el avatar, a veces estos aspectos quedan superados y simplemente el otro (el avatar). 
ISSN: 1794-9920 - ISSN Electrónico: 2500-9338

Enero - Julio de 2018

Volumen 18 Número 1, Año 2018 Págs. 82 - 91

A excepción de los nativos digitales, cuya probada seguridad del cuerpo digital los hace tales, en la cultura hipermediática, los transitorios, los itinerantes usuarios y algunos adultos vinculados tardíamente a la red, se atreven a cuestionar la posibilidad de que exista un cuerpo digital. Por eso ha sido tan difícil definir al avatar en términos de comprensión de sus rasgos de humano, su personalidad y los alcances comunicativos que pueda tener. Por eso también ha sido tan difícil hacer comprender a un sector de la población que este conjunto de bits también habla.

Las formas como el usuario construye el avatar se incorporan a nuevas maneras de hacerse a un cuerpo. En el cuerpo del usuario de la vida real y en el de avatar, los gestos y otras manifestaciones de la construcción del Yo actúan como signos; es decir, el cuerpo simboliza. En el cuerpo del usuario, los gestos son innatos, heredados 0 aprendidos; en cambio en el avatar son fabricados y, a veces, tienen un costo monetario.

\section{El componente psicológico}

Hay mucho de psicológico en el hecho de fabricar un avatar. Existe una motivación fuerte respecto a la recompensa que puede suscitar el hecho de poder convertirse en otra persona o incluso de cambiar de género y también a la estimulación emocional que ha permitido a los personajes superar la mera puesta en escena del avatar, para que en un momento dado pueda ser intervenido por los usuarios y se pueda transformar libremente cada vez que el usuario considere que ya no quiere hacer este o aquel tipo de gesto, que ya no quiere tener este 0 aquel color de cabello, de piel o que quiere ponerse unas prótesis.

La personalidad encarnada del avatar es continuamente interactuante, dialógica; su diálogo no siempre es verbal, sino que se regodea en las imágenes, los mundos, los estímulos emocionales, es decir, en aquellos aditamentos del programa que se le antojan deliciosos. Incluso, con la imagen pareciera descubrir nuevas potencialidades que van apareciendo en la complejidad de los mundos ofrecidos a su escogencia como ocurre en el cibermercado.

Estos mundos no son de construcción plana 0 lineal, sino las más de las veces se antojan retadores, por la complejidad de su construcción; incluso el usuario externo que al principio era una personalidad humana, es ahora un avatar manipulado por una conciencia externa cada vez menos fuerte. Incluso para muchos nativos digitales los cibermundos son una realidad sustituta de su mundo real. Pero en la pantalla se programan movimientos que pueden controlarse en los avatares y resultan muy estimulantes. De estos movimientos salen los comerciales y los discursos con los que luego se van a ver afectados los sistemas de cibermarketing y de marketing en el mundo real.

\section{CONCLUSIÓN:}

El tema del avatar que inspira el nacimiento del cyborg se extiende hacia los años 90's cuando se desarrolló el body art. Sin embargo, desde el punto de vista del marketing, aquellas motivaciones artísticas y contestarias que motivaron el movimiento liderado por Edward Kac, se han visto moduladas por el surgimiento de una nueva manera de expresión que atañe también a la cotidianeidad humana.

Es un modo de dialogar con el mundo en donde insertarse una prótesis es casi que un ejercicio cosmético. En cuanto a la creación de avatares, se observa en la actualidad una tendencia a buscar influenciadores de marca que estén inspirados en seres más emocionales que sean capaces de transformar las percepciones de los usuarios. Mientras los primeros funcionan en el llamado mundo tangible, los segundos se apoderaron del mundo virtual y desde allí responden a una programación que tienes un discurso y unos propósitos de marca que pueden volverse tendencia.

Este artículo responde a la necesidad de reflexionar sobre las nuevas tipos de relaciones que se generan en el ciberespacio y cómo estas posibilidades afectan las concepciones tradicionales de comunicaciones entre consumidores y marcas que se enfrentan en estos nuevos contextos, lo aquí expuesto es pues una revisión teórica y conceptual sobre cybors, avatares y portadores virtuales que permite hacer una contribución a este tema que si bien aún está poco explorado rápidamente a se ha convertido en algo más interesante para los estrategas del marketing. 


\section{REFERENCIAS:}

Aguilar, T. (2008). Ontología Cyborg.,El cuerpo en la nueva sociedad tecnológica. Gedisa. Barcelona.: Gedisa.

Bautista, L. D. (2013). Second Life: Factores humanos y nuevas formas de vivir en las redes sociales. En Tesis Doctoral. , . Bogotá.: Pontificia Universidad Javeriana.

brandlective. (24 de 04 de 2018). Obtenido de The Customer Avatar: An Essential Aspect of Every Marketing Strategy: https://www.brandlective.com/customer-avataressential-aspect-every-marketing-strategy/

brandwatch. (15 de 02 de 2017). Making Senses: Humans as Cyborgs. Obtenido de brandwatch: https://www.brandwatch.com/blog/makingsenses/

Campbell, N. O. (2005). Cyborg Consciouness-a Visual Culture Approach to the Technologised Body. European Advances in Consumer Research Volume 7, eds. Karin M. Ekstrom and Helene, 344-351.

Cinemania. (09 de 12 de 2014). cinemania.elmundo.es. Obtenido http://cinemania.elmundo.es/noticias/exclusivaposter-espanol-de-ex-machinal

Coleman, B., \& Shirky, C. (2011). Hello Avatar. Mit Press .

ECM Benchmarking Report - European Cities Marketing. (2018). European cities marketing. Obtenido de https://www.europeancitiesmarketing.com/europe an-cities-marketi...(2018) avalan este punto de vista

Haraway, D. (1996). A manifesto for Cyborgs: Science, technology, and socialist feminism in the 1980s. E.U.A: En Victor Vitanza (Ed.) CyberReader. E.U.A.: Allyn \& Bacon.

Harrell, D. F. (07 de September de 2018). The Coference. Obtenido de https://videos.theconference.se/dfox-harrell-impacts-of-the-avatar-dream

Illouz, E. (2007). ntimidades congeladas. Las emociones en el capitalismo. Madrid.: Katz ed. .

Joyanes. (1997). Cibersociedad. Los retos ante un Nuevo mundo digital. Madrid.: McGraw Hill. .
Kac, E. (1997). Bioarte.

Latour, B. (2007). Nunca Fuimos Modernos. Ensayo de antropología simétrica. Buenos Aires.: Siglo XXI,.

Machado, A. (2004). designisfels. Obtenido de Modos de agenciamiento y regimens de imersâo no ciberespa. co. Sesignis.: www. designisfels. net/designis5. htm.

Merca2.0, M. e. (23 de 11 de 2015). merca20. Obtenido de https://www.merca20.com/197366-2/

Nora, C. (18 de 02 de 2018). Neil Harbisson y su historia sobre cómo una antena en el cerebro le permite ver colores. México .

Perales, V. (2010). Revista Icono 14 No. 12., Pp201-217 ISSN 1697-8293. Madrid. .

Reeves, B., \& Read, L. (21 de 01 de 2010). Harvard Business Review. Obtenido de Employee Retention: Avatars in the Workplace

Sibilia, P. (2006). El hombre postorgánico: cuerpo, subjetividad y tecnologías digitales. Buenos Aires :F.C.E.

Strauss, A. L. (2002). Bases de la investigación cualitativa: técnicas y procedimientos para desarrollar la teoría fundamentada. Medellín: Medellín: Universidad de Antioquia.

Tendencias millonarias . (s.f.). Obtenido de ¿Qué es un AVATAR en Marketing Digital y para qué sirve?: https://tendenciasmillonarias.com/que-es-unavatar-en-marketing-digital-y-para-que-sirve/

Turkle, S. (1984). El segundo yo. Las computadoras y el espíritu humano. . Buenos Aires: Galápagos. 